\title{
Inclusive Approach: Hijra/Transgender Community
}

\author{
Ruchi Dubey Chaturvedi ${ }^{1}$, Ahad Dewoolkar ${ }^{2}$, Esha Sharma ${ }^{3}$, Kaizeen Mistry ${ }^{4}$, Sameer Parmar ${ }^{5}$ \\ ${ }^{1}$ Associate Professor, Department of Psychology, Jai Hind College, University of Mumbai, India \\ 2-5 TYBA students, Department of Psychology, Jai Hind College, University of Mumbai, India. \\ Corresponding author: Dr. Ruchi Dubey Chaturvedi \\ Email-ruchidc1@gmail.com
}

\begin{abstract}
Background and Objectives: The present study was undertaken to analyze the relationship between Social Support and the Six dimensions of Psychological Well Being of the 'Hijra'/transgender community, based in Mumbai.

Methods: A sample of 59 Transgender participants residing in Mumbai were selected randomly from Railway stations and Traffic signals. Their age range was from early adulthood (20yrs-40yrs) to middle adulthood (40yrs-60yrs). They were administered the Sarason Social Support Questionnaire and the Ryff's Scales of Psychological Well-Being. In Ryff's Scales of Psychological Well-Being they were assessed along six dimensions: i) Autonomy ii) Environmental Mastery iii) Personal Growth iv) Positive Relations v) Purpose in Life vi) Self-Acceptance. Data was analysed using Correlation Analysis and Scatter Plot.

Results: The results indicated that the participants were in the category- 'Below Average' in Social Support and in the category 'Moderate' on all the six dimensions of Psychological Well-Being. The relationship between Social Support and Psychological Well-being was found to be insignificant. Both the variables were independent of each other.

Conclusion: The results indicated that the Hijra community received below average Social Support. The participants of the Hijra community scored moderately on the six dimensions of Psychological Wellbeing.

Keywords: Hijra, Transgender, Eunuchs, Intersex people, Social Support, Psychological Well-Being, Autonomy, Environmental Mastery, Personal Growth, Positive Relations, Purpose in Life, SelfAcceptance.
\end{abstract}

(Paper received $-9^{\text {th }}$ March 2018, Peer review completed $-10^{\text {th }}$ April 2018)

(Accepted $-24^{\text {th }}$ April 2018)

\section{INTRODUCTION}

Hijras, as members of the eunuch, intersex or transgender community, are known to be a part of the Asian culture with historical evidence dating back to over 4,000 years. They are included in what is now commonly known as the 'third sex' and the LGBTQ spectrum. Despite finding a place in Indian mythology and history over ages, they find themselves at the receiving end of ridicule, abuse and discrimination in the society. They are found living at the fringes of society, with very low status, recognition and acceptance and often in inhuman conditions. This community is deprived of basic facilities integral to the human experience like healthcare, housing, education, employment, and legal/social rights. As regards their occupation and economic sustainability, they are known to make a living by ritualised ceremonies on occasions like childbirth and marriages in families, begging for alms on roads and in local trains, as sex workers and are considered deviant within the community [1].

The Hijras in India live within the 'guru-chela' (teacher-disciple) tradition, where the relationship is modelled on the construct of a teacher and disciple. The guru is expected to take care of the chela's needs, while the 
chela is expected to show respect and obedience to the guru and give the guru whatever they earn. Every Hijra joins the community under a guru, who ideally remains so for life. Gurus and chelas belong to the same "house," a nonlocalized symbolic descent group similar to a clan. The Hijra community is divided into approximately seven of these named houses (with some variation according to region). The heads of these houses within a particular city or geographical region form a council of elders, or jamat. This group makes important decisions for the community, is present at the initiation of new members, and resolves whatever disputes arise within the community. Hijra houses are not ranked and there are no meaningful cultural or social distinctions among them, but each house has its own origin story and certain rules of behaviour special to itself [2].

In India, the Hijra population is a staggering 4.88 lakh as per the 2011 census, with Maharashtra accounting for around $10 \%$ of the national whole.

\section{Hijra Lives: Negotiating Social Exclusion and Identities - Mrinalini Mazumdar [3]}

This research explores the lived realities of transgenders who enter the Hijra community and the various forms of social exclusion that these individuals face and the ways in which they respond, thereby shaping their identity. It focuses on the lives of the transgenders that helps construct their identity as a 'Hijra'. The symbolic interactionist perspective and labelling theory are used as theoretical anchors. Some of the main forms of exclusion that the respondents spoke of are familial ostracisation, physical and verbal abuse, forced sex, extortion of money and materials by the police and arrests on false allegations; restricted access to education, health services and public spaces and a severe curtailment of livelihood options. One of the significant coping mechanisms is the process of becoming members of a Hijra community and enrolling in a 'guru-chela' relationship. In exploring the nuances of this turn and the experience of exclusion, the study contributes to a discussion on the implementation of affirmative action by the state.

\section{Sexuality as a Human Right: Body, Desire and the State - Dr Pranta Patnaik [4]}

Bodies have always been a site of contestations, caught between realms of public laws and private desires. There have been studies focusing on the life of concealment by the LGBT community due to the laws made by the state, especially Sec.377 of Indian Penal Code. In recent times, the government has recognised the protection of the rights of transgenders, which surprisingly contradicts their fundamental rights. Employing Foucault's concept of the panoptic on, the paper engages with the laws related to the LGBT community. It reveals how the state makes a distinction between acceptable bodies and unacceptable desires with an attempt to regulate the bodies of its citizens. The sexual state tries to demean their existence and control their destiny by making their private sexual conduct a crime. The paper argues that the realm of individual desires should not be subject to scrutiny by the public laws under the garb of morality and desirability. The article ends with possible strategies that need to be identified and undertaken by each stakeholder to ensure a life of dignity for people belonging to LGBT community.

\section{Families They Choose: Examining the Hijra Family and Relations [5]}

Challenging the dominant definitions of hetero-normative families, the paper throws light on families epitomised by Hijras, who, often as a result of rejection by their natal families, come to form their own kinship networks and so far have not been covered in the existing body of scholarship on alternative family arrangements. Based on ethnographic data and narratives collected from Hijra Deras of Delhi, this paper seeks to discuss the nuances of families outside of a 'monolithic understanding' of family. The broad argument of the paper revolves around the role played by families of choice in the building of the Hijra identity and also deepening and enriching the existing discourse on families in India.

\section{Understanding the Mental Health of the Hijra Women of India [6]}

LGBT populations like the Hijra have a higher prevalence of mental health issues compared to their heterosexual counterparts. They are also more vulnerable to alcohol and substance use disorders. According to a study, $48 \%$ of Hijra participants suffered from psychiatric disorders ranging from alcohol abuse and dependence to depressive spectrum disorders to gender identity disorders. Despite this presence, none have ever had psychiatric consultation for these issues due to perceived and real stigma from health professionals. 


\section{Hijras/Transgender Women In India: HIV, Human Rights and Social Exclusion [7]}

Social Exclusion Framework is increasingly used in highlighting the issues and problems faced by disadvantaged and disenfranchised groups. Adapting the SEF to Hijras, once can understand how these communities have been excluded from effectively participating in social and cultural life, economy, politics and decision-making processes. It assumes the following forms:

- Exclusion from social and cultural participation:

$>$ Exclusion from family and society

$>$ Lack of protection from violence

$>$ Restricted access to education, health services and public spaces.

- Exclusion from economy

$>$ Exclusion from all levels of the economy

$>$ Exclusion from employment and livelihood opportunities.

- Exclusion from politics and citizen participation

$>$ Restricted access to collectivization

$>$ Restricted rights of citizenship

$>$ Restricted participation in decision-making processes

\section{Let Us Live: Social Exclusion of Hijra Community [8]}

Hijras face multiple forms of oppression across all areas of life. Due to their predominantly feminine behaviours they are ousted from home. They are harassed verbally, physically, sexually and mentally, in private and the public spaces. As a result, their human dignity and self-esteem is diminished and they report feeling worthless and unfit to live in society. This was especially so in the case of middle-aged Hijras. They also reported no hope for survival. This research reported no safe socio-political space where they can lead their lives with basic dignity.

\section{The Invisible Ones: Sexual Minorities [9]}

Sexual minorities recognize that they are different from the 'majority others', during their adolescence. Many of them end up in marital/heterosexual relationships against their will because of family and societal pressure. These marriages end up in marital disharmony, divorce or continue with poor quality of life. Legal inheritance is often denied by their family members. They are not allowed inside the premises of the educational institutions. Hence, illiteracy is very common among this sexual minority. They are not considered for government jobs. Even if they have a job, they are suspended from the job once their gender identity/sexual orientation is revealed. Discrimination and non-friendly environment at work place force them to take up begging and prostitution for their livelihood.

\section{To Be Some Other Name: The Naming Games that Hijras Play [10]}

There are multiple names that Hijras take during their life course: index changes in bodies, kinship status, and position within their social milieu. These name-changing practices also encode the erosion of relationships and the hopes for new and different futures. But as subjects of the state, Hijras multiple names create problem for both them and others.

\section{Trajectories of the Transgender: Need to Move from Sex to Sexuality [11]}

The unifocal attention on HIV/AIDS and the targeting of the transgender people have further marginalized and excluded these populations by branding them as repositories of the virus and as high-risk groups. The Hijras are trapped in a vicious cycle of market and medicine and it is here that the state needs to intervene with policies for welfare and programs for inclusion.

Narrating Identity: The Employment of Mythological and Literary Narratives in Identity Formation Among the Hijras of India 
This research explores how the Hijras and Kinnars of India use mythological narratives in identity-formation. Mythological and literary narratives play a significant role in explaining and legitimising behavioural patterns, ritual practices, and anatomical forms that are specific to Hijras. This paper focuses on certain narratives that Hijras employ to make sense of and giving meaning to their lives, including mythological stories concerning people of ambiguous gender and myths associated with Bahuchara Mata.

\section{METHODOLOGY}

\section{Aim}

To study the relationship between social support and psychological well-being of the Hijra/transgender community.

\section{Hypotheses}

H1 - The Hijra community is receiving low level of Social Support.

$\mathrm{H} 2$ - The Hijra community is experiencing low level of Psychological Well-Being.

H3 - Social Support will enhance the Psychological Well-Being of the Hijra community as there exist positive correlation between them.

\section{Variables}

Independent Variable: Psychological Well-Being

Dependent Variable: Six dimensions of Psychological Well-Being

\section{Operational Definitions of Variables}

1. Social Support: Support from kith and kin, associates and society at large

2. Six Dimensions of Psychological Well-Being:

i. Autonomy: self-determination and independence

ii. Environmental Mastery: competence in managing external activities

iii. Personal Growth: continued development and openness to new experiences

iv. Positive Relationship: satisfying and trusting relations with others

v. Purpose in life: sense of direction and goals in life

vi. Self-Acceptance: acknowledgement of the self and positive attitude

\section{Sample}

\section{Inclusive Criteria}

- Sample: 59 members of the Hijra/transgender community, sourced informally from railway stations and traffic signals.

- Age range of participants was from Early Adulthood (20yrs-40yrs) and Middle Adulthood (40yrs$60 \mathrm{yrs})$

- All the participants were residing in all-hijra communities

\section{Exclusion Criteria}

- Hijras staying with their biological families

- Hijras who were part of formal organizations like, NGOs

- Hijras who were younger than 20 yrs and older than $60 \mathrm{yrs}$

\section{Design}

Primary data collected will be collected by Snowball sampling method. Repeated Measures Design will be used where all the participants will be administered the two Psychological tests

\section{Tools}

i) Sarason Social Support Questionnaire (Short Form) [12] 


\section{Procedure}

All the participants were contacted at different railway signals and traffic signals. Maintaining research ethics, they were assured that their response and identities will be kept confidential. After rapport formation they were personally and individually administered Sarason Social Support Questionnaire and Ryff's Scales of Psychological Well-Being. After data collection each participant was debriefed and thanked.

\section{RESULTS AND DISCUSSION}

Table 1: Mean, SD \& Level of Social Support and Psychological Well-Being $(\mathrm{N}=59)$

\begin{tabular}{|l|c|c|c|}
\hline & MEAN & SD & LEVEL \\
\hline Social Support & 2.68 & 0.76 & Below Average \\
\hline \multicolumn{2}{|c|}{ DIMENSIONS OF PSYCHOLOGICAL WELL-BEING } \\
\hline Autonomy & 12.305 & 2.793 & Moderate \\
\hline Environmental Mastery & 13.305 & 1.734 & Moderate \\
\hline Personal Growth & 12.966 & 1.434 & Moderate \\
\hline Positive Relationship & 13.169 & 3.547 & Moderate \\
\hline Purpose in Life & 9.694 & 3.119 & Moderate \\
\hline Self Acceptance & 11.779 & 3.119 & Moderate \\
\hline
\end{tabular}

This leads to the acceptance of $\mathrm{H} 1$ as it was predicted that Social Support being received by the Hijra community from the family and society would be low. However, $\mathrm{H} 2$ is rejected as it was predicted that Hijra Community would be experiencing low level of Psychological wellbeing. The sample is experiencing Moderate level of Psychological wellbeing, as assessed along its six dimensions. This leads to the conclusion that Social Support is having negligible effect on Psychological Wellbeing. Further, the in-group support which Hijra Community offers each other is ensuring that they experience. Moderate level of Psychological Wellbeing.

Social Support is not correlated with any of the six dimensions of Psychological Well-Being. Hence, for the participants there is insignificant effect of Social Support on their Psychological Well-being. This leads to the rejection of $\mathrm{H} 3$ as it was proposed that Social Support will have positive correlation with Psychological Wellbeing.

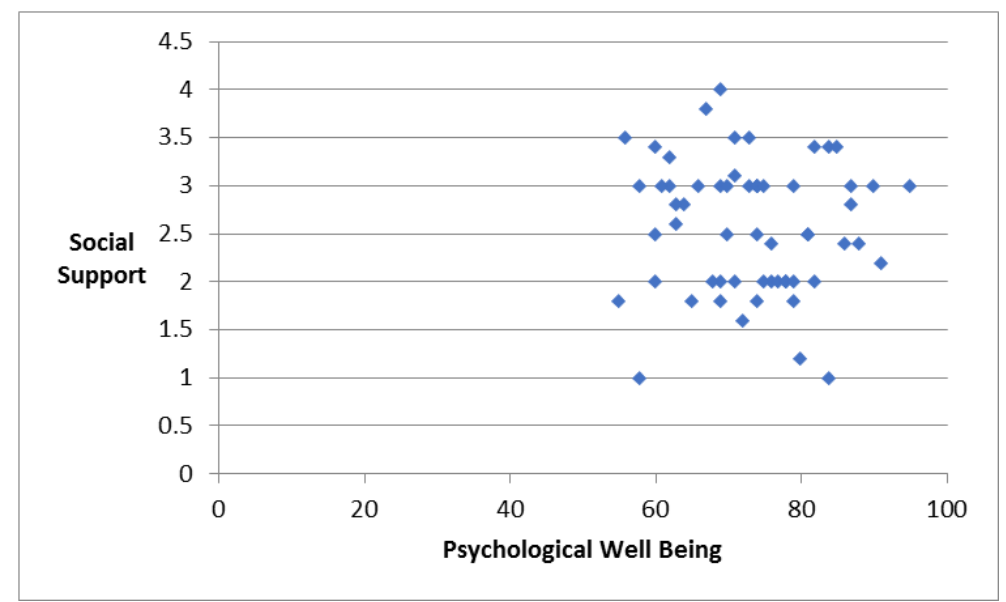

Figure 1: Scatter Plot showing relationship between Social Support and Psychological Well-Being (N=59) 
Social Support is independent of Psychological Well-Being. So, Social Support cannot predict Psychological Well-Being.

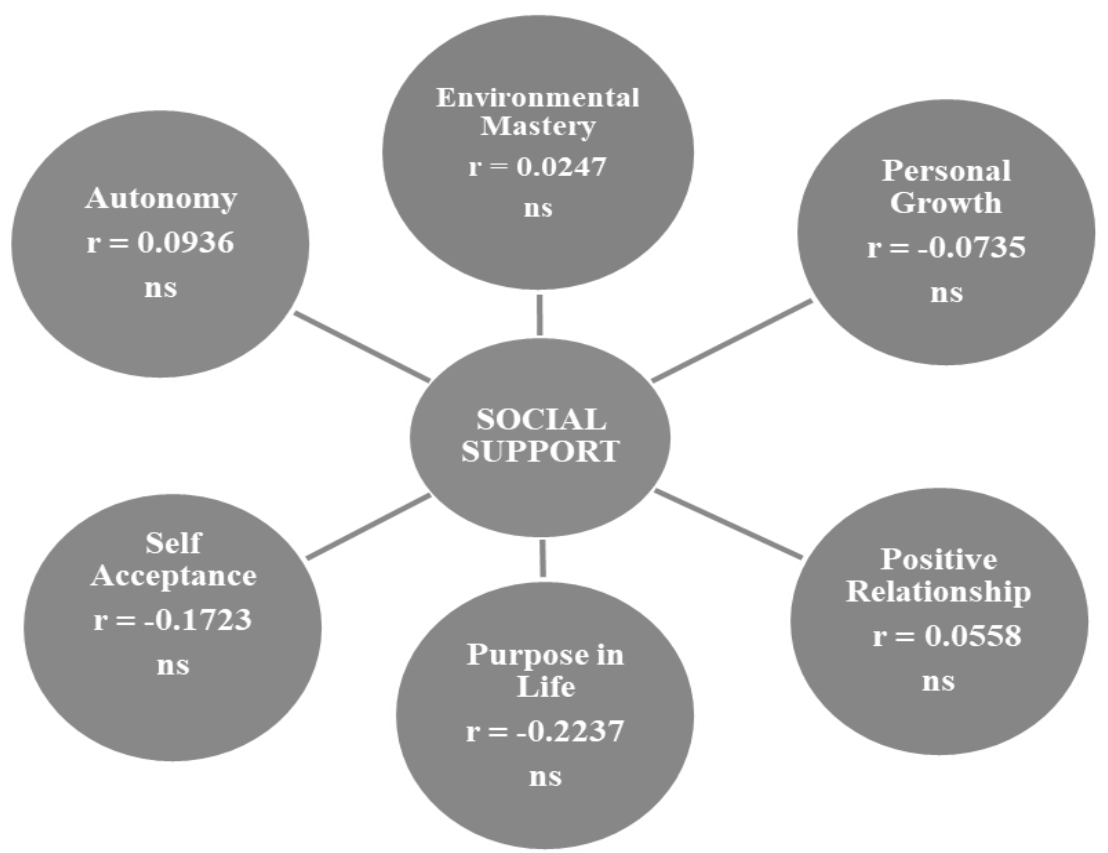

\section{CONCLUSION}

- The results indicated that the Hijra community received below average Social Support. The participants of the Hijra community scored moderately on the six dimensions of Psychological Wellbeing.

- The Social Support does not significantly correlate with Psychological Wellbeing of the Hijra community. This could be the reason for the Hijra Community participants getting below average Social Support, but are still able to experience moderate levels, on all the six dimensions, of Psychological Well-being.

- These were in line with the observations made by past research in the area. While the Hijra community are getting adequate support from their in-group members, there is a lack of acceptance and support from society in general.

- To bring the marginalized Hijra community to the manifold of the society, just extending them social support might not be enough.

\section{Future Implications and Applications}

- Destigmatization and humanization should be a norm now while dealing with the Hijra community

- Other variables like Life Satisfaction, Self-Esteem, Intelligence and Emotional Intelligence can also be investigated to understand the Hijra community better.

- Adequate assistance must come from out-group members and the society via:

$>$ Legal cover

$>$ Government policies and regulations

$>$ Equal opportunities for personal growth and development

$>$ Financial empowerment by providing jobs in mainstream workforce

$>$ Education and enlightenment of the masses 


\section{Scope for Future Research}

- To study if variables like, discrimination, job opportunities correlate with the Psychological Wellbeing of the Hijra community.

- To conduct the research on Hijras in other metropolitan cities and small towns.

- To compare the Social Support received by the Hijra community in different states of India.

- To study the prevalence of Psychological disorders like, Substance Abuse, Sexual Disorders, Depression, Anxiety, Life Skills, in the Hijra community and assess the frequency of interventions and treatment sought by them.

\section{Limitations}

- Limited sample size

- Restricted to Mumbai city

- Limited variables explored

- No interaction with family or friends

- Hijras staying in formalized institutions and with biological families were not studied

- Hijras who were adolescents or senior citizens were not studied

\section{REFERENCES}

1. Kalra G, Shah N. The cultural, psychiatric, and sexuality aspects of hijras in India. Int J Transgenderism 2013;14(4):171-81.

2. Kalra G. Hijras: the unique transgender culture of India. Int J Culture Ment Health 2012;5(2):121-6.

3. Mazumdar M. Hijra Lives: Negotiating Social Exclusion and Identities. (Doctoral dissertation, Tata Institute of Social Sciences).

4. Taparia S. Emasculated bodies of Hijras: Sites of imposed, resisted and negotiated identities. Indian J Gender Stud 2011;18(2):167-84.

5. Aasaavari A, Mohapatra S, Sharma A. Families They Choose: Examining the Hijra Family and Relations. Indian J Soc Work 2016;77(4):459-78.

6. Jayadeva V. Understanding the Mental Health of the Hijra Women of India. American Journal of Psychiatry Residents' Journal 2017;12(05):7-9.

7. Chakrapani V, Babu P, Ebenezer T. Hijras in sex work face discrimination in the Indian health-care system. Res Sex Work 2004;7:12-4.

8. Mal S. Let us to live: Social exclusion of Hijra community. Asian J Res Soc Sci Humanities 2015;5(4):108-17.

9. Math SB, Seshadri SP. The invisible ones: Sexual minorities. Indian J Med Res 2013;137(1):4-8.

10. Saria V. The Pregnant Hijra. Living and Dying in the Contemporary World: A Compendium. 2015 Nov 17:83.

11. Goel I. Hijra communities of Delhi. Sexualities 2016;19(5-6):535-46.

12. Sarason IG, Levine HM, Basham RB, Sarason BR. Assessing social support: The social support questionnaire. J Personal Soc Psychol 1983;44(1):127-33.

13. Ryff CD. Happiness is everything, or is it? Explorations on the meaning of psychological well-being. J Personal Soc Psychol 1989;57(6):1069-87.

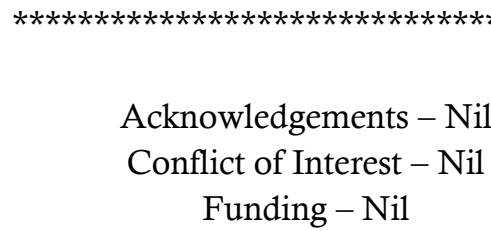

